Smith, Esmie, Hill, Andrew P. ORCID:

https://orcid.org/0000-0001-6370-8901, Mallinson-Howard, Sarah H. ORCID: https://orcid.org/0000-0002-8525-1540 and Gustafsson, Henrik (2020) Stress, Burnout and Perfectionism in Soccer Players. In: Dixon, Joe, Barker, Jamie, Thelwell, Richard and Mitchell, lan, (eds.) The Psychology of Soccer. Routledge

Downloaded from: http://ray.yorksj.ac.uk/id/eprint/4486/

The version presented here may differ from the published version or version of record. If you intend to cite from the work you are advised to consult the publisher's version: https://www.routledge.com/The-Psychology-of-Soccer-1st-Edition/Dixon-Barker-ThelwellMitchell/p/book/9780367350284

Research at York St John (RaY) is an institutional repository. It supports the principles of open access by making the research outputs of the University available in digital form. Copyright of the items stored in RaY reside with the authors and/or other copyright owners. Users may access full text items free of charge, and may download a copy for private study or non-commercial research. For further reuse terms, see licence terms governing individual outputs. Institutional Repository Policy Statement

\title{
RaY
}

Research at the University of York St John

For more information please contact RaY at ray@yorksj.ac.uk 
Smith, E. P., Hill, A. P., Mallinson-Howard, S. H., \& Gustafsson, H. Stress, Burnout and Perfectionism in Soccer Players. To appear in J. Dixon, J. Barker, R. Thelwell, I. Mitchell (Eds.), The Psychology of Soccer. Accepted 12-04-2019.

\title{
Stress, Burnout and Perfectionism in Soccer Players
}

\author{
Esmie P. Smith ${ }^{1}$, Andrew P. Hill ${ }^{1}$, Sarah H. Mallinson-Howard ${ }^{1}$, \\ \& Henrik Gustafsson ${ }^{2}$ \\ ${ }^{1}$ York St John University \\ ${ }^{2}$ Karlstad University
}

\begin{abstract}
Author Note
Correspondence should be addressed to Andrew P. Hill, School of Sport, York St John

University, York, YO31 7EX, United Kingdom. Telephone: +441904 876365 e-mail: a.hill@yorksj.ac.uk.
\end{abstract}




\section{Stress, Burnout and Perfectionism in Soccer Players}

\section{Brief Induction and Review of Literature}

Pursuing and maintaining a career as a professional soccer player is stressful. The journey to become a professional soccer player starts with formal registration to a club's academy from the age of 9 years old. Thereafter, players undergo increasingly demanding training and regular reviews to secure their place at the club. The decision as to whether a player is awarded a professional contract is normally made when the player is aged 18 to 23 years old, representing in some cases 14 years of investment. With less than $1 \%$ of academy players achieving professional status, the process is fiercely competitive and most who start the journey are unsuccessful (Green, 2009). For those who make it into the professional team, they will typically have the security of only a two-year contract or less. Over a third will move club every season, often leaving their families to join clubs in different parts of the country or sometimes abroad. And, in all, their career will typically last only 8 years after which most will need to seek alternative employment with minimum education or training in any area other than soccer (FIFPro, 2016; Roderick \& Schumacker, 2016).

With these circumstances in mind, the aim of this chapter is to provide an overview of stress and burnout processes in soccer and explain why some soccer players are more susceptible to the development of stress and burnout than others. We first define and describe stress and burnout, and then we review research examining burnout in soccer players. Thereafter, we define and describe perfectionism, a common personality trait among athletes, and highlight how this trait may place soccer players at greater risk to burnout. This includes a review of research that has examined the relationship between perfectionism and burnout in 
soccer players. Finally, we provide an illustrative case study of how perfectionism fueled burnout can manifest in soccer and how it was managed by a sport psychologist.

\section{Stress as a Process}

There are several different ways to understand stress. One of the most popular in psychology is the Transactional Model of Stress (TMS; Lazarus \& Folkman, 1984). In this model, "stress" is not a specific outcome or emotion. It is an internal psychological process that governs emotional experiences more broadly. To be "stressed" denotes the activation of this process and the experience of a range of unpleasant emotions (e.g., anxiety, fear and frustration). A number of key concepts are important to understanding stress as a process. The term "stressor" is used to identify an event or situation that can trigger the stress process (Lazarus, 1991). “Appraisal” corresponds with a personal, typically unconscious, evaluation of the significance and consequences of the demands associated with the stressor. And, finally, "coping" refers to the specific strategies that are deployed to deal with demands. There are a wide range of different coping strategies that people can use but coping strategies can broadly be categorized as emotion-focused (how we attempt to manage our emotions), problem-focused (how we attempt to remove a stressor), or avoidant (how we attempt to avoid or escape a stressor) (Lazarus \& Folkman, 1984).

In terms of the sequence of events in the stress process, when a stressor occurs the appraisal process begins. There are two types of appraisal that take place. First, primary appraisal takes place to ascertain if a stressor is irrelevant, positive, negative or harmful (e.g., “is losing this match important to my goals?”). Next, if the stressor has personally meaningful consequences, secondary appraisal takes place so to ascertain available coping resources to deal with the stressor (e.g., "do I have the ability to perform how I want to or how I am expected to?") (Lazarus, 1991). What kind of coping strategies are deployed depends on the appraisal of resources with problem-focused coping normally used when resources are high 
and avoidant coping normally used when resources are low. Although what determines if individuals are successful in their attempts to cope is complex, problem-focused coping is typically regarded to be a better way of coping than avoidant coping and emotion-focused coping when utilized regularly (Biggs, Brough, \& Drummond, 2017).

It is important to note that experiencing stress is part of everyday life and is not problematic for most people. In accord, many soccer players will successfully cope with the stressors they encounter whereas others will not. The stress process takes into account this individuality in the way in which appraisal is influenced by an individual's values, goals and beliefs. As these can be different for everyone, the personal meaning and significance of any event will also differ from person to person, as will perceptions of personal resources. This means that two individuals can respond quite differently to the same event. That said, there are events and personality characteristics that are more likely to make most people prone to stress. For instance, research has found that certain stressors are common among soccer players and include performance demands (e.g., making mistakes), team issues (e.g., relationships with teammates), coach issues (e.g., coaches personality), and practical issues (e.g., travel management) (Holt \& Hogg, 2002; Kristiansen, Murphy, \& Roberts, 2012; Reeves, Nicholls, \& McKenna, 2011). It is consideration of these environmental factors and the different characteristics of the soccer players themselves that help us identify who is more susceptible to stress and its consequences.

\section{Athlete Burnout and Burnout in Soccer players}

One consequence of long-term stress is athlete burnout. Burnout was first studied in organizational psychology (e.g., Maslach, 1993). The relevance of burnout to sport was first recognised by Raedeke (1997; Raedeke \& Smith, 2001) and it has since become a popular area of research for sport psychologists (see Gustafsson, DeFreese, \& Madigan, 2017). Raedeke (1997) proposed that athlete burnout is characterized by three core symptoms: 
physical and emotional exhaustion, a reduced sense of accomplishment, and sport devaluation. In regard to these symptoms, physical and emotional exhaustion is fatigue that is experienced beyond that which would arise because of the typical demands of sport participation. When this symptom is high, athletes feel sapped of energy and have difficulty recovering a sense of vigour. A reduced sense of accomplishment, by contrast, is the perception of feeling inadequate and ineffective. Athletes perceive that they are consistently performing below their capabilities or unable to reach their goals, regardless of their actual success. Finally, sport devaluation is a decreased interest in sport participation. This is when athletes develop cynical attitude and resentment towards their sport and may choose to drop out.

In terms of understanding how these symptoms develop, Smith (1986) has produced one of the best supported models of athlete burnout. In this model, athlete burnout is the result of chronic "overload" in the stress process. Mirroring the stress process, burnout includes the longstanding experience of high environmental stressors (high competitive demands, low social support, low autonomy, and low rewards) and low resources (perceived or actual insufficient skills/ability to cope with demands). The appraisals involved in burnout reflect a sense of being overwhelmed by demands with little means to manage them effectively or gain any respite. The three core symptoms of burnout themselves are actually part of a broader psychological response in the stress process that includes a range of negative emotions (e.g., anxiety and anger), physiological reactions (e.g., fatigue, insomnia, and illness susceptibility) and behavioural signs (e.g., decreased performance and avoidant coping strategies).

The prevalence of burnout in sport and soccer is currently unknown. This is because there has been no systematic attempt to estimate the number of athletes or soccer players exhibiting burnout and its symptoms in existing studies. However, for this chapter we 
collated all studies that have examined burnout in soccer. To do so we conducted a computerized search of published research using the databases PsycINFO, PsycARTICLES, MEDLINE, and SPORTDiscus. The search terms were burnout AND soccer. The search date was between January 1990 and December 2018. The search was limited to peer-review journals published in English. The search produced 54 studies. The abstract of each study was reviewed, and studies removed that did not provide an empirical examination of burnout exclusively in soccer players or were duplicates. The number of studies was reduced to $\mathrm{k}=$ 17. There was one further published peer-review article that we were aware of but that were not retrieved through the review (Smith, Hill, \& Hall, 2018). Information provided in Table 1 is from these published articles.

Most studies we identified used the Athlete Burnout Questionnaire (ABQ; Raedeke \& Smith, 2001) to measure burnout. This is a self-report questionnaire that has five questions for each of the three symptoms. Each question is measured on a five-point scale that indicates how often an athlete experiences a symptom: 1 = "almost never", 2 = "rarely", $3=$ "sometimes", 4 = "frequently" and 5 = "almost always". To interpret the questionnaire, an average total burnout score and an average score for each symptom is calculated. There is no cut-off or threshold for the questionnaire that signals when an athlete has burned out. Therefore, in Table 1 we have reported the percentage of athletes that report an average of 3 out of 5 and 4 out of 5 (i.e., soccer players who reported experiencing symptoms "sometimes" and "frequently"). We adopted this approach for all other instruments too.

When examining the prevalence of total burnout across studies, it was found that the percentage of athletes who typically reported experiencing total burnout sometimes was $7.1 \%$ (range $<1 \%$ to $18.4 \%$ ) and frequently was $<1 \%$ (range $0 \%$ to $1.4 \%$ ). When observing the individual burnout symptoms, it was found that the percentage of athletes who typically report experiencing exhaustion sometimes was $18.4 \%$ (range $<1 \%$ to $38.6 \%$ ) and frequently 
was $2.2 \%$ (range $0 \%$ to $6.3 \%$ ). The percentage of athletes who typically report experiencing reduced accomplishment sometimes was $14.8 \%(<1 \%$ to $44.0 \%)$ and frequently was $<1 \%(0 \%$ and $4.9 \%$ ). Finally, the percentage of athletes who typically report experiencing sport devaluation sometimes was $7.9 \%(<1 \%$ and $32.6 \%)$ and frequently was $<1 \%(0 \%$ to $1.8 \%)$. These figures reveal that burnout is not especially common but, nonetheless, can be observed to some degree in most groups of soccer players.

The studies providing evidence of prevalence also examined burnout alongside a range of other factors and in various groups. Of the eighteen studies reviewed, five of the samples were adult soccer players and the rest were adolescent soccer players. Two of the five adult samples were identified as being professionals and one as being semi-professionals. Eleven of the eighteen adolescent samples were from soccer academies of professional clubs. In all, fifteen of the samples were all male, one was all female, and two were a mix of males and females. Regarding the factors examined, the studies typically focused on how burnout was related to (1) features of the training and performance environment created by others, particularly the coach, and (2) individual features such as personal motives for participating in soccer and other personality characteristics. We have provided the correlation coefficient between the different features and burnout symptoms in each study in Table 1. Correlation coefficients range from -1.00 to +1.00 . A positive correlation coefficient signals that as the feature increases burnout increases and a negative correlation coefficient signals that as the feature increases burnout decreases. Larger correlation coefficients signal stronger relationships.

Regarding features of the training and performance environment, burnout among soccer players has typically been found to be higher when they report that coaches are more controlling and autocratic. That is, when the soccer player has little or no input in to decision making. Similarly, burnout has also been found to be higher when soccer players report that 
coaches, teammates and parents thwart their needs for competence (belief in personal abilities), relatedness (feeling connected to others) and autonomy (being in control of one's actions/life). By contrast, burnout has typically been found to be lower among soccer players when they report higher social support, autonomy support, and a democratic coach style. This means that when soccer players report support from others (social support), are given choice without coercion or pressure (autonomy support), and their opinions are taken into account (democratic style), burnout is less likely. Similarly, research has found that burnout is lower among soccer players when they report others are satisfying their needs of competence, relatedness, and autonomy. Finally, burnout has also been found to be lower when soccer players report receiving positive feedback and believe the coach is satisfied with their goal progress.

Regarding individual features, burnout among soccer players has been found to be lower when soccer players report higher harmonious passion (i.e., that they are choosing to take part of their own volition and due to a sense of value in the sport) and when participation is accompanied by other positive features such as enjoyment, hope, and subjective vitality (i.e., positive feelings of energy). In contrast, burnout has typically been found to be higher among soccer players when they report obsessive passion (i.e., their motives include a sense of being compelled to participate because they "have to") and when participation is accompanied by other negative features, such as stress, anxiety, and depressive symptoms. The personality characteristic that has received the most attention is perfectionism. Burnout has been found to be higher when soccer players report some aspects of perfectionism and lower when the report other aspects of perfectionism (Hill, 2014; Hill et al., 2008; Smith et al., 2018). Because of the potential importance of perfectionism, we now focus on this characteristic and the mechanisms underpinning its relationship with burnout.

\section{Multidimensional Perfectionism}


Perfectionism is a trait that is broadly defined as the pursuit of exceedingly high standards accompanied by overly critical evaluations (Frost, Marten, Lahart, \& Rosenblate, 1990). In Hewitt and Flett's (1991) popular model, perfectionism comprises three dimensions: self-oriented perfectionism (SOP), socially prescribed perfectionism (SPP) and other-oriented perfectionism (OOP). SOP is self-directed and is a requirement of perfection from the self ("I expect myself to be perfect"). Those high in SOP set their own high personal standards and adopt a harsh critical style when evaluating themselves. SPP is the perception that other people have unrealistically high standards (“Others expect me to be perfect"). Those high in SPP believe that perfectionistic standards are imposed on them and if standards are not met they will be subjected to harsh criticism from others. Finally, OOP is externally directed ("Others should be perfect"). Those high in OOP have unrealistic expectations for others and when standards are not met it leads to harsh criticism of others.

Hewitt and Flett (2002) argued that perfectionism is associated with four stress related mechanisms. The first mechanism pertains to how perfectionism creates more stressful events by encouraging individuals to pursue unrealistic rather than appropriate goals (stress generation). The second mechanism pertains to how perfectionism contributes to a greater preoccupation with possible stressors and their personal significance (stress anticipation). The third mechanism pertains to how perfectionism can maintain and prolong stress because of a tendency to overthink and obsess during stressful episodes (stress perpetuation). The fourth and final mechanism pertains to how irrational beliefs can subvert appraisal processes so that even minor events are considered monumentally important, mistakes are considered indicative of profound personal flaws, and coping becomes avoidant and ineffective (stress enhancement). Given the close association of stress and burnout, these same mechanisms also explain why perfectionism may contribute to the development of burnout in athletes.

\section{Perfectionism and Burnout in Soccer Players}


At present, there are three studies that have examined the relationship between perfectionism and athlete burnout in soccer. In the first study, Hill et al. (2008) examined the relationship between perfectionism and burnout and whether unconditional self-acceptance (accepting oneself regardless of approval from others) mediated or explained this relationship. One hundred and fifty-one adolescent male soccer academy players took part in the study ( $M$ age $=14.53$ years, $S D=2.29$ years $)$. All players completed questionnaires that measured perfectionism, burnout and unconditional self-acceptance on one occasion. It was found that SPP had a positive relationship with all burnout symptoms whereas SOP had a negative relationship with all burnout symptoms. In addition, unconditional self-acceptance partially mediated the relationship between both dimensions of perfectionism and burnout. That is, the view that one needs to constantly win approval from others linked both SOP and SPP to higher burnout in soccer players.

In the second study, Hill (2013) examined the relationships between combinations of dimensions of perfectionism and burnout. This included high levels of SOP and high levels of SPP, low levels of both, and a mix of low and high SOP and SPP. One hundred and sixtyseven adolescent male soccer academy players took part in the study ( $M$ age $=16.17$ years, $S D=1.57$ years). All players completed measures of perfectionism and burnout. Findings revealed that (i) low SOP/high SPP was related to higher levels of total burnout and all symptoms of burnout in comparison to individuals exhibiting low levels of perfectionism, (ii) High SOP/low SPP was related to lower levels of total burnout and reduced accomplishment in comparison to those individual exhibiting low levels of perfectionism, (iii) a mix of high SOP/high SPP was related to lower levels of total burnout, reduced accomplishment and sport devaluation in comparison to those exhibiting low SOP/high SPP, and (iv) a mix of high SOP/high SPP was related to higher total burnout, reduced accomplishment and exhaustion than those exhibiting high SOP/low SPP. Based on these findings, low SOP/high SPP and 
high SOP/high SPP are the worst combinations of perfectionism for soccer players in terms of burnout.

In the most recent study, Smith, Hill, and Hall (2018) examined the relationships between perfectionism, burnout, and depressive symptoms over time. One hundred and eight adolescent male soccer academy players $(M$ age $=16.15$ years, $S D=1.84)$ completed measures of perfectionism, burnout, and depressive symptoms twice three months apart during the competitive season. The findings showed that the relationships between perfectionism and burnout are more complex when observed over time. SOP did not predict any burnout symptoms over time nor was it predicted by any burnout symptoms. However, the relationships between SPP and burnout were reciprocal with SPP related to increases in sport devaluation over three months and sport devaluation also related to increases in SPP over the same time period. In other words, while perceptions that others expect you to be perfect can increase burnout in soccer players, the experience of burnout may itself lead to a greater reliance on others' expectations to maintain participation. The implications being young soccer players may become entrapped; participating because they believe they "have to" rather than because they "want to".

In summary, so far, research examining perfectionism and burnout in soccer players demonstrates that SPP is problematic for soccer players, particularly as the relationship between SPP and burnout has been found over time. As such, early indication is that SPP is a risk factor for burnout among soccer players. In comparison to SPP, SOP has a more complex relationship with burnout. SOP has a negative relationship with burnout when measured on one occasion, a positive indirect relationship via conditional self-acceptance, and no relationship when examined over time. The role of SOP in the development of burnout among soccer players is therefore currently unclear. In keeping with these findings, when examining combinations of perfectionism, it is the presence of high SPP either in 
combination with high or low SOP that is important and what makes soccer players most at risk of burnout.

\section{Practical applications - Case study}

Next, we present a case study of perfectionism fuelled burnout in soccer. The case study is a based on the experience of one of the authors from their applied work. We have altered some of the details and circumstances, so the individual remains anonymous. However, overall, the case study documents similar issues to those presented by athletes in his actual work and the steps that were taken to help address these issues.

\section{Background and context}

Jen is a 22-year-old elite level soccer player. She had been part of the national squad for two years and was in her first season at one of the major professional clubs in Europe. She combined her soccer career with university studies and planned to be a lawyer after her soccer career was over. She had recently moved towns and clubs so to allow her to continue her studies. This move was also partly motivated by the belief that playing for the new club would give her a better chance of becoming a starting player in the national team. As a consequence of her move, her life changed significantly, with new teammates, new coaches and new surroundings. The sport psychologist was introduced to Jen at the new club where he worked part-time. A few weeks into the competitive season Jen sought him out to discuss what she described as "motivation issues."

\section{Presenting issue(s)}

Jen reported in informal conversations with the sport psychologist that she was struggling with the workload of combining studying with soccer and always felt tired. The coach had also made comments about her apparent lethargy to both the player and the sport psychologist. From what Jen described, it appeared that she was displaying signs of mental 
and physical exhaustion. She was not currently in the first team at the club and she reported that she was performing poorly, well below the perfectionistic standards she had for herself and the levels that she believed helped her secure the move to the club. She said that she found her new teammates to be friendly but, overall, the environment at the club was far more competitive than her previous club so she wanted to be professional about her interactions with her teammates. Jen said that because she has little time to do other things and meet new people she felt isolated and lonely. Sometimes she cried at night when she was on her own due to the pressure of her new life and feelings of stress.

\section{The intervention/work conducted}

Intervention work with Jen included eight formal sessions. Reflecting the experience and expertise of the sport psychologist, the sessions were guided by cognitive behaviour therapy (CBT). CBT is a short-term, problem-focused, goal directed therapy with roots in both behavioural and cognitive therapy (Craske, 2017). It is based on two basic premises. First, that our cognitions influence our emotions and behaviours. Second, that our behaviours influence our emotions and cognitions (Wright, Basco, \& Thase, 2006). It is thought to be an effective intervention for perfectionism because individuals displaying perfectionistic tendencies typically have negative thoughts and irrational beliefs associated with the need to be perfect. The sport psychologist had also used CBT when working with other athletes reporting similar issues. In formulating the approach, the intervention work was guided by Egan, Wade, Shafran, and Antony (2014).

\section{Session 1: Initial analysis}

The aim of the first session was to provide some initial analysis of the issues being presented and Jen's reasons for wanting to change. The principles of CBT were also explained and the typical sequence of the work outlined. 
The session started by asking why Jen was seeking support and what she thought she needed help with. Jen said she was here because she was feeling stressed and had started to feel low in motivation. She described having no energy for training and feeling tired. She was asked to describe an ordinary day in detail. Jen indicated that she had two training sessions per day with the soccer club, one in the morning (10.00-11.30 am) and one in the evening (17.00-18.30 pm). She attended university classes in between. She had decided that this was not enough training and so had also added an extra session in the morning before breakfast (7.00-8.00 am). She also tended to complete a "light" training session on her rest days (days when players were instructed by the club not to train). The extra training was being both positively reinforced ("I feel good about myself as I was doing something the other players were not") and negatively reinforced ("If I don't do it, I get anxious and worry that I am not doing enough"). She estimated that with her additional training sessions and sessions on rest days, she had trained more than anyone at the club. This was something she was proud of.

Jen mentioned that she considered herself to be a perfectionist. When discussing her goals and expectations it was clear that Jen was extremely demanding of herself. These demands seem to be tied to proving to others that she is both an exceptional student and soccer player. Her father was a professional soccer player and had been instrumental in her career so far. She referred to his achievements and advice often. Her only sibling, an older brother, was also an elite level athlete and had competed internationally with some notable successes. The need to "prove herself" equal to her brother and win the approval of her father was a reoccurring theme when she described her motivation and why soccer was important to her.

Her perfectionism was also evident in how she prepared for matches and training. Jen prepared meticulously for training as to when and what she ate, and always arrived at training and matches early, well before her teammates and sometimes before her coaches. She also 
kept detailed notes on her own performances in the form of a performance diary (something her father recommended). She did not like to rest and always liked to be doing something, even on rest days when she completed her own separate training sessions. Generally, she considered being a perfectionist to be a good thing. However, she also acknowledged that when things didn't go well in games or training, she had difficulty focusing. She got angry with herself and others often but hid her anger from others. The worst moments were when the team lost and she had performed badly. When this happened, she felt ashamed and guilty, and contemplated leaving soccer completely.

\section{Session 2: Case formulation, behavioral and functional analyses}

The aim of the second session was to develop a case formulation of the issues Jen presented and then conduct an analysis of her behavior. In doing so, a conceptual framework and set of working hypotheses for the problem and its consequences was created.

Through discussion, an initial picture of Jen's problem was constructed including how it developed and what was maintaining it. This focused on her mental and physical fatigue, and approaches to training and competition. A "problem list" was created that made explicit what the key issues were (e.g., "Tired all the time" and "Feel like I am letting people down"). This included discussing what the short-term and long-term consequences of these problems if they were not addressed (e.g., "I won't perform to my ability" and "I will probably have to leave the club") and the benefits of addressing these problems (e.g., "I will feel better about myself'). This was an important step for building an alliance with Jen and fostering a commitment in her for the work ahead. It was decided that the problem list and a list of the consequences would be copied into the start of her performance diary.

After outlining the problems that Jen was experiencing in behavioral terms, functional analysis was conducted so to understand the relationships between the antecedents, behaviours and the consequences. A functional analysis can help clarify the role of 
perfectionism and the influence it has on the well-being of the individual and can also help determine whether you should focus on the treatment of perfectionism first, the treatment of the symptoms first (here, mental and physical exhaustion), or on both together. As part of Jen's functional analysis, we focused on the origins and consequences of her perfectionistic and rigid way of thinking which had inadvertently become tied to the belief that she "needed to always be professional." This is illustrated in Figure 1. This allowed us to identify specific distorted ways of thinking/cognitive biases and how her extra training and over-preparation were safety behaviors (i.e., being used to prevent or minimize negative things happening). In concert with Jen, the extra training, over-preparation, and lack of physical "down time" were identified as the major source of Jen's feelings of exhaustion. In addition, her perfectionistic tendencies, self-criticism, and the unrealistic demands that she placed on herself were identified as major sources of the psychological stress she was experiencing.

Session 3: Psychoeducation and self-monitoring

The aim of the third session was to discuss some of the myths regarding perfectionism. In addition, perfectionistic thoughts and associated emotions and dysfunctional behaviors that Jen was engaging in, as well as their perceived function, were also focused upon.

In this session the psychologist described and discussed the problems associated with perfectionism such as myths like "practice makes perfect". It was important to show Jen that being less perfectionistic didn't mean lowering her standards and help her take a broader view of her participation in soccer. Also, importantly, addressing perfectionism meant she would need to focus more on how she felt about herself when things were not perfect and why she felt that way. By presenting how her thoughts, emotions and behaviors were linked, this provided a rationale for the interventions that were designed later. Via structured questioning ("Socratic dialogue"), Jen's thoughts about possible disadvantages of her current 
behaviors were explored. One important insight was that the extra morning training sessions may be undermining her ability to rest, recover, and perform well the following day. A further insight was how her meticulousness and over-preparedness made it difficult for her to get mental respite from soccer and her studies.

Jen was introduced to the notion of monitoring her perfectionistic way of thinking. She was asked to provide examples of some of the thoughts she had ("my preparation needs to be perfect"), how strongly she believed the thought ("95\%"), what behaviors followed ("turning up an hour early to training"), and how this made her feel ("anxious"). Using a small number of examples, the discussion focused on how productive or counter-productive the subsequent behaviors and feelings were. Jen was asked to spend some time doing this alone for other thoughts and behaviors and to bring her attempts to the next session where they could be discussed. She was provided with a worksheet to record this exercise.

\section{Session 4: Behavioral experiments and inflexible standards}

The aim of the fourth session was to introduce the use of behavioral experiments and to co-create behavioral experiments that could be used to test the problematic behaviors identified as part of the problems.

Undertaking behavioral experiments with clients is a way for them to gather information themselves first-hand and to test unhelpful thoughts and beliefs. Jen had identified several counterproductive behaviors related to both sport and university work. These included staying up all night studying and comparing her performances with her teammates despite differences in age, experience, and playing positions ("I always need to be better than the others"). Different behavioral experiments were considered in context of the practicalities (what behavioral experiments were feasible) and her own apprehension (what behavioral experiments felt challenging but manageable). She did not want to include other players or coaches in the experiments. It was agreed that Jen should skip three of the extra 
morning training session until the next meeting (two days with extra training and then three days without it) and then evaluate the consequences. This behavioral experiment was designed to test the validity of the beliefs she held that "more training was better than less," "the extra training is helping my performance," and "the extra training makes me feel better." As part of the behavioral experiment she was asked to monitor how tired she felt each day (0$100 \%)$, how well she performed in the other training sessions (0-100\%), and how positive she felt $(0-100 \%)$.

Session 5: Evaluating behavioral experiments and new insights

The aim of the fifth session was to review Jen's experience of the behavioral experiment and for her to reflect on the experience.

Jen described how the assignment had been tough and had provoked a lot of anxiety. However, she also reported that after a few days she felt like she had more energy and was more alert during training sessions. She reported that this helped her confidence. Reflecting upon the behavioral experiment, she compared how she used to feel during training camps with the junior national team ("full of energy") and how she had been feeling ("exhausted") and identified the additional training and lack of fun as major sources of her lethargy. Her new insights and further discussion about what it means to be "professional" formed the basis of the session. Her initial beliefs were revisited and she had the opportunity to rephrase them. In each case, the beliefs were revised based on her experience ("the right amount of training is important" and "I feel best when I am rested and can perform well"). It was decided that Jen would skip the additional morning training sessions and training sessions on rest days and see how she felt. It was also agreed that she should continue to challenge her thinking errors and explore the consequences of changing other behaviors such as turning up on time (not too early) and planning fun events such as socializing with friends on her rest days (as opposed to training). 


\section{Session 6: Challenging cognitive biases}

The aim of session six was to challenge the excessive concerns Jen expressed regarding mistakes and explore how this was linked to some of her beliefs.

Jen was first asked if she was a player that always needed to be in control and feel comfortable (rating 0-100\%). She replied, 100\%. The second question was whether she was a player that wanted to learn new things and to develop (rating 0-100\%). She replied, $100 \%$. The sport psychologist then proceeded to discuss the compatibility of these two answers with Jen. In addition, it was discussed how she viewed other members of her team, the standards she had for herself and others, and her selective attention to the errors she makes while discounting positive aspects of her performances. This latter issue was evident in her performance diary that focused almost exclusively on the mistakes she had made and technical weaknesses. It was agreed that she would record at least the same amount of positive aspects of her performance as negative aspects in her performance diary (e.g., "ability to pass with backspin from left foot has got better").

Building on the monitoring exercise in an earlier session, Jen was introduced to the idea of using a thought diary and consciously challenging and amending her negative thoughts (cognitive restructuring) and behaviors. This process was modelled in the session with the help of the sport psychologist. Jen was asked to "think aloud" as the sport psychologist described various scenarios she might encounter. This included turning up late to training, making a mistake in training, and not being selected to be a starter in the team for an important match. Afterwards, her thoughts were recorded and reviewed with a focus on identifying which thoughts were "helpful" or "harmful" towards her performances. The reasoning behind the decision was discussed and, for thoughts identified as "harmful," alternative thoughts were created. For example, "I need to prove myself to the coaches" was replaced with "the coaches believe in me and want me to be successful" and "if I am late, 
people will think I am not professional" was replaced with "even the best players at the club are late sometimes". It was also agreed that this exercise would be a regular part of her own performance diary.

\section{Session 7: Scheduling time for recovery and pleasant events}

The aim of session seven was to help Jen understand that she could balance her participation in soccer with time for rest and relaxation.

Individuals demonstrating perfectionism often feel that they must always be doing something productive. One important aspect of Jen's problems was related to insufficient mental recovery. Insufficient recovery is a critical aspect of burnout. Jen thought that "doing more was better" and she made little time for activities other than soccer or university study. Social events were the last things on her "to-do-list" even though she would have benefited from the social support and distraction that can be provided by time with friends and family. The focus of the session was on the different ways she might spend her "rest day" (the one day of the week the club did not ask her to come to the club). After considering various options Jen decided she would like to join a recreational canoeing club. This was one of her hobbies she enjoyed with friends before moving towns. She felt it would allow her to meet new people, people who were not involved in soccer, and still be active (but not too active). It was also decided that Jen should talk with her coach about whether he had ideas about how her recovery could be improved. Finally, it was decided that Jen should talk to her father about the pressure she feels. Jen and her father had a brief conversation when she moved to the new club and she thought it was a good idea to follow up this up and be more open about the experiences she had been having.

Session 8: Maintenance and relapse prevention

The aim of the final session was to focus on ensuring that Jen was ready to bring the sessions to a close and could maintain the work we had done together. 
Jen had good news. Her talk with her father had been a relief. He was very

understanding and had shared some of his own experiences. He also told her that he provided advice and was eager to help because he wanted her to feel supported. He didn't want her to feel pressure from him. With the coach, she also planned several changes that would help her recovery. The coach stressed the importance of balancing "light days" and "heavy days" so her body could recover. Hearing the coach encourage her to rest more was important to Jen. One of the main goals of CBT is that the athlete becomes conscious of their own thoughts and able to manage them, in effect becoming self-sufficient. In this respect, the athlete should be able to better handle future challenges without the sport psychologist. This session helped prepare Jen for this by creating an action plan. This plan was developed based on questions from Butler, Fennell and Hackman (2008): How did the problem(s) develop? What kept them going (maintenance)? What have you learned (insights, methods etc.)? What were your most unhelpful thoughts and do you have alternatives? How can you build on what you have learned to continue working in the right direction? What will help me do this? Jen copied this into the back of her performance diary.

\section{Outcome analysis and case study reflections}

Working with Jen was challenging. She found it difficult to discuss the issues that she thought underpinned her behaviours and was particularly sensitive to discussing scenarios in which she wasn't successful at the club. The idea that she would become a lesser player, or even mediocre, if she accepted anything less than perfection from herself meant that she was also initially reluctant to considering that she might need to address her perfectionism. Some key turning points in this regard were the notion that being less perfectionistic did not mean lowering her standards. The behavioural experiments, too, were useful as it gave Jen something "to do" and provided tangible outcomes. Her physical recovery improved almost immediately once she stopped the extra training sessions and, in turn, so did her 
performances and, in turn, confidence. She recognised this and so did her coaches. As such, the intervention was considered successful. Jen found it more difficult to "switch off" psychologically but some of the related over-preparation was reduced (e.g., turning up extremely early) and she was able to find more opportunities for other activities as she better integrated into the new town. The advice from the coach regarding the importance of rest appeared to legitimise her attempts to "recover better" as did the coaches idea that "being good at rest also takes practice.” The importance of Jen's father was evident at various junctures. Jen benefited from being more open with him and he responded by adopting a more overtly supportive role. This was reassuring to Jen and helped dispel her fears that how he felt about her depended on her success as a soccer player.

\section{Summary and Conclusions}

In this chapter we provided an overview of stress and burnout processes in soccer. In doing so, we explained how risk of burnout is influenced by both the soccer environment and the characteristics of the soccer players. In these regards, research has found that soccer players report higher burnout when their coaches, teammates and parents are perceived to be less supportive and when their participation was accompanied by less enjoyment and less internal motives for taking part (i.e., participating because they want to). We also identified perfectionism as an especially important personality characteristic in terms of risk of burnout in soccer players. In particular, perceptions that others expect you to perform perfectly, when accompanied by internal pressures to be perfect or on its own, has consistently been found to be related to higher burnout in soccer players. With this in mind, our case study of an elite female soccer player illustrated how sport psychologists can work effectively with players by using a CBT approach to help manage burnout when it is underpinned by perfectionistic thoughts and behaviours.

\section{Key Messages and Further Reading}


Below we provide five key messages from the chapter and related directions for future research.

1. Soccer is an environment in which stressors are common. Common stressors include performance pressures, managing relationships with others, and day-to-day practicalities of being in a sport environment. Research is increasingly looking at how sport is organised and what features might lead to more stress or less stress for athletes (see Fletcher, Hanton, \& Mellalieu, 2008). An increased focus on the structure of soccer in this regard is likely to offer further insight into burnout.

2. There are currently no accepted cut-off points to identify when soccer players (or athletes generally) are burned out or not. Our review revealed that the percentage of soccer players who typically reported experiencing burnout symptoms sometimes ranged between $7.1 \%$ and $18.4 \%$ and frequently ranged between $<1 \%$ to $2.2 \%$. Other reviews are required like ours to compare these figures to other sports.

3. Several environmental and personal factors have been identified in research that are related to burnout in soccer players. However, the last review of research examining athlete burnout in all sports was over ten years ago (Goodger, Gorely, Lavallee, \& Harwood, 2007). As there has been a considerable amount of research since publication of the review, an updated review is sorely needed. This should include a focus on comparing different sports. 4. Perfectionism is emerging as a key characteristic when seeking to identify soccer players who are at risk to burnout. However, so far, only a small number of studies exist, all are in male adolescent academy players, and there has been only one examination of this relationship over time (3 months). To better establish perfectionism as a risk factor, research is required that examines the perfectionism-burnout relationship in a wider range of soccer settings including in adults, females, more elite groups (e.g., professional soccer players), and over prolonged periods of time (e.g., an entire season). 
5. Very few studies have been published that have documented or formally evaluated interventions aimed at reducing athlete burnout. Research that does so is a priority. In the meantime, and so to better inform future work of this kind, researchers and practitioners should consult work outside of sport (e.g. Awa, Plaumann, \& Walter, 2010).

Below are five key further readings for those interested in learning more about the topic;

DeFreese, J. D., Raedeke, T., \& Smith, A. L. (2014). Athlete burnout: An individual organizational phenomenon. In J. M. Williams \& V. Krane (7th ed.), Applied Sport Psychology: Personal Growth to Peak Performance (444-461). New York, NY:

McGraw-Hill.

Gustafsson, H., DeFreese, J. D. \& Madigan, D. J. (2017). Athlete burnout: Review and recommendations. Current Opinion in Psychology, 16, 109-113.

Hill, A. P. (2016). Conceptualizing perfectionism: An overview and unresolved issues. In A. P. Hill (Ed.), The Psychology of Perfectionism in Sport, Dance, and Exercise (pp. 3-30). London: Routledge. ISBN 9781138958692

Jowett, G. E., Mallinson, S. H., \& Hill, A. P. (2016). An independent effects approach to perfectionism in sport, dance, and exercise. In A. P. Hill (Ed.), The Psychology of Perfectionism in Sport, Dance, and Exercise (pp. 85-149). London: Routledge. ISBN 9781138958692

Smith, A. L., Pacewicz, C. E. \& Raedeke, T.D. (2019). Athlete burnout in competitive sport. In T. S. Horn \& A. L. Smith (Eds.), Advances in sport and exercise psychology $\left(4^{\text {th }}\right.$ ed., pp. 409-424). Champaign, IL: Human Kinetics. 


\section{References}

Adie, J. W., Duda, J. L., \& Ntoumanis, N. (2012). Perceived coach autonomy support, basic needs satisfaction and the well- and ill-being of elite youth soccer players: A longitudinal investigation. Psychology of Sport and Exercise, 13, 51-59.

Awa, W. L., Plaumann, M., \& Walter, U. (2010). Burnout prevention: A review of intervention programs. Patient Education and Counseling, 78, 184-190

Balaguer, I., Gonzalez, L., Fabra, P., Castillo, I., Merce, J., \& Duda, J. L. (2012). Coaches’ interpersonal style, basic psychological needs, and the well- and ill-being of young soccer players: A longitudinal analysis. Journal of Sports Sciences, 30, 1619-1629.

Biggs, A., Brough, P., \& Drummond, S. (2017). Lazarus and Folkman's psychological stress and coping theory. In C. L. Cooper, \& J. Campbell Quick (Eds.), The handbook of stress and health: A guide to research and practice (pp. 351-364). West Sussex, UK: Wiley-Blackwell.

Blakelock, D. J., Chen, M. A., \& Prescott, T. (2016). Psychological distress in elite adolescent soccer players following deselection. Journal of Clinical Sport Psychology, 10, 59-77.

Butler, G., Fennell, M., \& Hackman, A. (2008). Cognitive-behavioral therapy for anxiety disorders: Mastering clinical challenges. New York, NY: Guilford Press.

Cheval, B., Chalabaev, A., Quested, E., Courvoisier, D. S., \& Sarrazin, P. (2017). How perceived autonomy support and controlling coach behaviors are related to well- and ill-being in elite soccer players: A within-person changes and between-person differences analysis. Psychology of Sport and Exercise, 28, 68-77.

Craske, M. G. (2017). Cognitive-behavioral therapy. Washington, DC: American Psychological Society. 
Curran, T., Appleton, P. R., Hill, A. P., \& Hall, H. K. (2011). Passion and burnout in elite junior soccer players: The mediating role of self-determined motivation. Psychology of Sport and Exercise, 12, 655-661.

Curran, T., Appleton, P. R., Hill, A. P., \& Hall, H. K. (2013). The mediating role of psychological need satisfaction in relationships between types of passion for sport and athlete burnout. Journal of Sports Sciences, 31, 597-606.

Egan, S. J., Wade, T. D., Shafran, R., \& Antony, M. M. (2014). Cognitive-behavioral treatment of perfectionism. New York, NY: Guilford Press.

FIFPro. (2016). 2016 FIFPro global employment report: Working conditions in professional football. Retrieved from https://www.fifpro.org/attachments/article/6706/2016\%20FIFPro\%20Global\%20Surv ey\%20-\%20TopFindings_1128.pdf

Fletcher, D., Hanton, S., \& Mellalieu, S. D. (2008). An organizational stress review: Conceptual and theoretical issues in competitive sport. New York, NY: Nova Science.

Frost, R. O., Marten, P. A., Lahart, C., \& Rosenblate, R. (1990). The dimensions of perfectionism. Cognitive Therapy and Research, 14, 449-468.

Gonzalez, L., Garcia-Merita, M., Castillo, I., \& Balaguer, I. (2016). Young athletes perceptions of coach behaviors and their implications on their well- and ill-being over time. Journal of Strength and Conditioning Research, 30, 1147-54.

Gonzalez, L., Tomas, I., Castillo, I., Duda, J. L., \& Balaguer, I. (2017). A test of basic psychological needs theory in young soccer players: Time-lagged design at the individual and team levels. Scandinavian Journal of Medicine \& Science in Sports, $27,1511-1522$. 
Gouttebarge, V., Aoki, H., \& Kerkoffs, G. (2015). Symptoms of common mental disorders and adverse health behaviours in male professional soccer players. Journal of Human Kinetics, 49, 277-286.

Gouttebarge, V., Backx, F. J. G., Aoki, H., \& Kerkhoffs, G. M. (2015). Symptoms of common mental disorders in professional football (soccer) across five European countries. Journal of Sports Science and Medicine, 14, 811-818.

Gouttebarge, V., Frings-Dresen, M. H. W., \& Sluiter, J. K. (2015). Mental and psychosocial health among current and former professional footballers. Occupational Medicine, 65, 190-196.

Green, C. (2009). Every boy's dream. London, UK: A \& C Black Publishers.

Goodger, K., Gorely, T., Lavallee, D., \& Harwood, C. (2007). Burnout in sport: A systematic review. The Sport Psychologist, 21, 127-151.

Gustafsson, H., Skoog, T., Podlog, L., Lundqvist, C., \& Wagnsson, S. (2013). Hope and athlete burnout: Stress and affect as mediators. Psychology of Sport and Exercise, 14, 640-649.

Gustafsson, H., DeFreese, J. D., \& Madigan, D. J. (2017). Athlete burnout: Review and recommendations. Current opinion in psychology, 16, 109-113.

Hewitt, P. L., \& Flett, G. L. (1991). Perfectionism in the self and social contexts: Conceptualization, assessment, and association with psychopathology. Journal of Personality and Social Psychology, 60, 456-470.

Hewitt, P. L., \& Flett, G. L. (2002). Perfectionism and stress processes in psychopathology. In G. L. Flett \& P. L. Hewitt (Eds.), Perfectionism: Theory, research and treatment (pp. 255-284). Washington, DC: American Psychological Association. 
Hill, A. P. (2013). Perfectionism and burnout in junior elite soccer players: A test of the $2 \times 2$ model of dispositional perfectionism. Journal of Sport \& Exercise Psychology, 35, $18-29$.

Hill, A. P. (2014). Perfectionistic strivings and the perils of partialling. International Journal of Sport and Exercise Psychology, 12, 302-315.

Hill, A. P., Hall, H. K., Appleton, P. R., \& Kozub, S. A. (2008). Perfectionism and burnout in junior elite soccer players: The mediating influence of self-acceptance. Psychology of Sport and Exercise, 9, 630-644.

Holt, N. L., \& Hogg, J. M. (2002). Perceptions of stress and coping during preparations for the 1999 women's soccer world cup finals. The Sport Psychologist, 16, 251-271.

Isoard-Gautheur, S., Oger, M., Guillet, E., \& Martin-Krumm, C. (2010). Validation of a French Version of the Athlete Burnout Questionnaire (ABQ). European Journal of Psychological Assessment, 26, 203-211.

Kristiansen, E., Murphy, D., \& Roberts, G. (2012). Organizational stress and coping in U.S professional soccer. Journal of Applied Sport Psychology, 24, 207-223.

Lai, C., \& Wiggins, M. S. (2003). Burnout perceptions over time in Division I soccer players. International Sports Journal, 7, 120-127.

Lazarus, R. S. (1990). Theory-based stress measurement. Psychological Inquiry, 1, 3-13.

Lazarus, R. S. (1991). Progress on a cognitive-motivational-relational theory of emotion. American Psychologist, 46, 819-834.

Lazarus, R. S., \& Folkman, S. (1984). Stress, appraisal and coping. New York, NY: Springer.

Li, C., Ivarsson, A., Stenling, A., \& Wu, Y. (2018). The dynamic interplay between burnout and sleep among elite blind soccer players. Psychology of Sport and Exercise, 37, 164-169. 
Lopes Verardi, C. E., Nagamine, K. K., Neiva, C. M., Pessona Filho D. M., Micelli Domingos, N. A., Ciolac, E. G., \& Santos Miyazaki, M. C. D. (2014). Burnout and playing position: A study of Brazilian soccer players. Journal of Physical Education and Sport, 14, 324-330.

Lopes Verardi, C. E., Nagamine, K. K., Micelli Domingos, N. A., De Marco, A., Santos Miyazaki, M. C. D. (2015). Burnout and pre-competition: A study of its occurrence in Brazilian Soccer Players. Revista de Psicologia del Deporte, 24.

Malach-Pines, A. (2005). The burnout measure short version. International Journal of Stress Management, 12, 78-88.

Maslach, C. (1993). Burnout: A multidimensional perspective. In W. B. Schaufeli, C. Maslach, \& T. Marek (Eds.), Series in applied psychology: Social issues and questions. Professional burnout: Recent developments in theory and research (pp. 1932). Philadelphia, PA, US: Taylor \& Francis.

Maslach, C., \& Jackson, S. E. (1981a). The measurement of experienced burnout. Journal of Organisational Behaviour, 2, 99-113.

Maslach, C., \& Jackson, S. E. (1981b). The Maslach Burnout Inventory: Research Edition. Palo Alto, CA: Consulting Psychologists Press.

Pires, D. A., Brandao, M. R. F., \& Silva, C. B. (2006). Validação do questionário de burnout para atletas. Revista da Educação Física, 17, 27-36.

Price, M. \& Weiss, M. (2000). Relationships among coach burnout, coach behaviors, and athletes' psychological responses. The Sport Psychologist, 14, 391-409.

Prinz, B., Dvorak, J., \& Junge, A. (2016). Symptoms and risk factors of depression during and after the football career of elite female players. BMJ Open Sport \& Exercise Medicine, 2, 1-6. 
Raedeke, T. D. (1997). Is an athlete burnout more than just stress? A sport commitment perspective. Journal of Sport and Exercise Psychology, 19, 396-417.

Raedeke, T. D., \& Smith, A. L. (2001). Development and preliminary validation of an athlete burnout measure. Journal of Sport and Exercise Psychology, 23, 281-305.

Reeves, C. W., Nicholls, A. R., \& McKenna, J. (2011). The effects of a coping intervention on coping self-efficacy, coping effectiveness, and subjective performance among adolescent soccer players. International Journal of Sport and Exercise Psychology, 9, 126-142.

Roderick, M., \& Schumacker, J. (2016). 'The whole week comes down to the team sheet': A footballer's view of insecure work. Work, Employment, and Society, 31, 166-174.

Shafran, R., Cooper, Z., \& Fairburn, C. G. (2002). Clinical perfectionism: A cognitivebehavioural analysis. Behaviour Research and Therapy, 40, 773-791.

Smith, A. L., Gustafsson, H., \& Hassmen, P. (2010). Peer motivational climate and burnout perceptions in adolescent athletes. Psychology of Sport \& Exercise, 11, 453-460.

Smith, E. P., Hill, A. P., \& Hall, H. K. (2018). Perfectionism, Burnout and Depression in Youth Soccer Players: A longitudinal study. Journal of Clinical Sport Psychology, 12, 179-200.

Smith, R. E., (1986). Toward a cognitive-affective model of athletic burnout. Journal of Sport Psychology, 8, 36-50.

Tabei, Y., Fletcher, D., \& Goodger, K. (2012). The relationship between organizational stressors and athlete burnout in soccer players. Journal of Clinical Sport Psychology, 6, 146-165.

Van Yperen, W. (1997). Inequality and vulnerability to dropout symptoms: An exploratory causal analysis among highly skilled young soccer players. The Sport Psychologist, $11,318-325$. 
Wright, J. H., Basco, M. R., \& Thase, M. E. (2006). Learning Cognitive-Behavior Therapy: An Illustrated Guide. Washington: DC. American Psychiatric Press.

Yildiz, S. M. (2011). Relationship between leader-member exchange and burnout in professional footballers. Journal of Sports Sciences, 29, 1493-1502. 


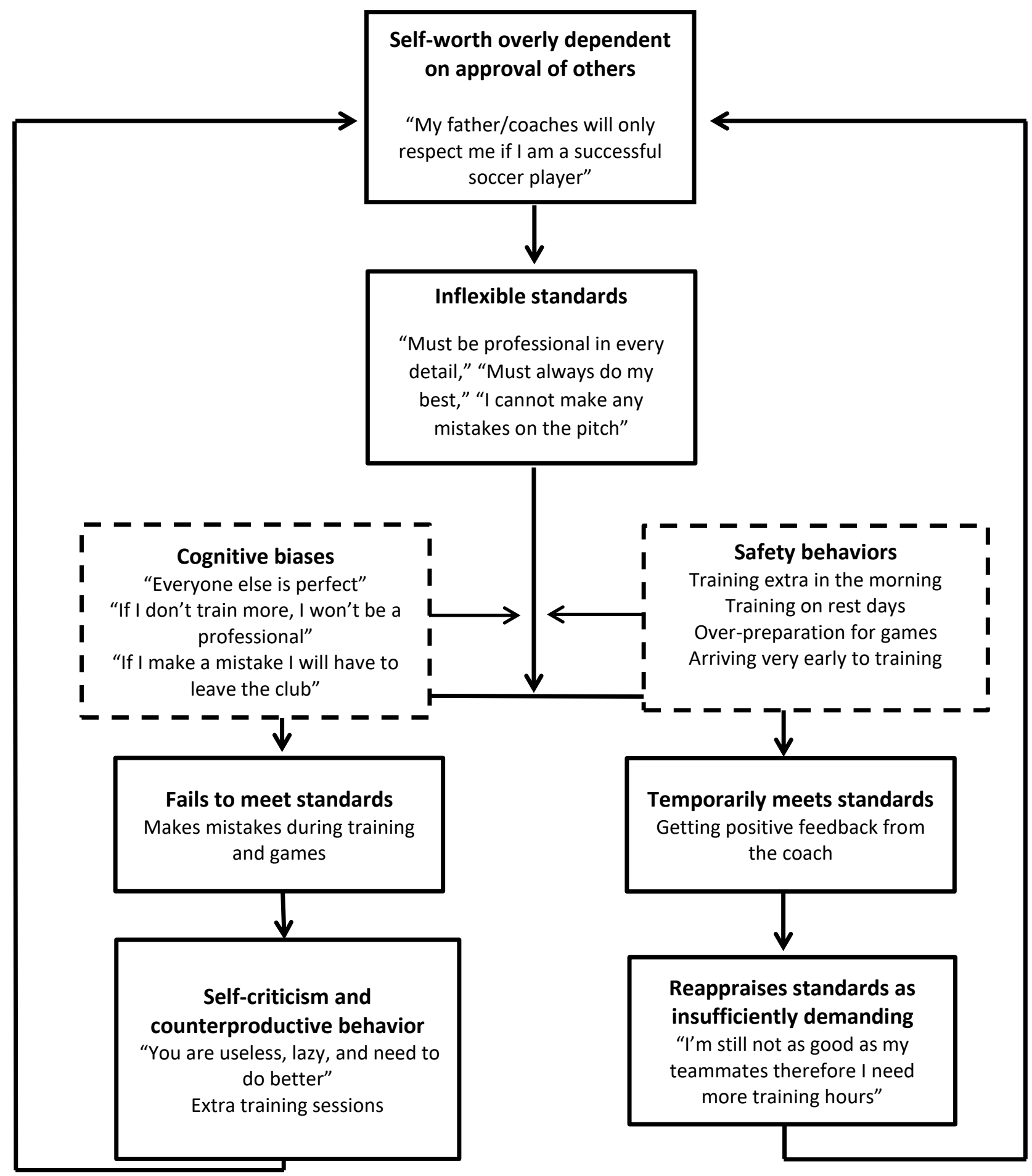

Figure 1. A cognitive behavioural model of Jen's perfectionism. Based on the cognitivebehavioural model of perfectionism presented by Shafran, Copper, and Fairburn (2002; p.780). 
Table 1 - A summary of research examining burnout in soccer players $(k=18)$

BO RA EE DEV

\begin{tabular}{|c|c|c|c|c|c|c|c|c|c|c|c|c|}
\hline \multirow[t]{2}{*}{ Study } & \multirow[t]{2}{*}{ Sample } & & \multicolumn{4}{|c|}{ Burnout prevalence } & \multirow[t]{2}{*}{ Instru. } & \multirow[t]{2}{*}{ Criterion variable } & \multirow[t]{2}{*}{$r$} & \multirow[t]{2}{*}{$r$} & \multirow[t]{2}{*}{$r$} & \multirow[t]{2}{*}{$r$} \\
\hline & & & $M$ & $S D$ & $\begin{array}{c}\text { Sometimes } \\
(\%)\end{array}$ & $\begin{array}{c}\text { Frequently } \\
(\%)\end{array}$ & & & & & & \\
\hline \multirow[t]{16}{*}{$\begin{array}{l}\text { Adie, Duda, \& } \\
\text { Ntoumanis (2012) }\end{array}$} & $\begin{array}{l}91 \text { male junior soccer academy } \\
\text { players }(\mathrm{M}=13.82 ; \mathrm{SD}=1.99)\end{array}$ & Exhaustion (T1) & 1.91 & 0.76 & 7.64 & 0.30 & $\mathrm{ABQ}$ & Autonomy support (T1) & - & - & -.25 & - \\
\hline & & & & & & & & Autonomy (T1) & - & - & -.03 & - \\
\hline & & & & & & & & Competence (T1) & - & - & -.05 & - \\
\hline & & & & & & & & Relatedness (T1) & - & - & -.11 & - \\
\hline & & & & & & & & Subjective vitality (T1) & - & - & -.31 & - \\
\hline & & Exhaustion (T2) & 2.03 & 0.85 & 12.71 & 1.02 & & Autonomy support (T2) & - & - & -.21 & - \\
\hline & & & & & & & & Autonomy (T2) & - & - & -.04 & - \\
\hline & & & & & & & & Competence (T2) & - & - & -.18 & - \\
\hline & & & & & & & & Relatedness (T2) & - & - & -.10 & - \\
\hline & & & & & & & & Subjective vitality (T2) & - & - & -.32 & - \\
\hline & & Exhaustion (T3) & 2.31 & 1.01 & 24.83 & 4.75 & & Autonomy support (T3) & - & - & -.30 & - \\
\hline & & & & & & & & Autonomy (T3) & - & - & -.07 & - \\
\hline & & & & & & & & Competence (T3) & - & - & -.32 & - \\
\hline & & & & & & & & Relatedness (T3) & - & - & -.17 & - \\
\hline & & & & & & & & Subjective vitality (T3) & - & - & -.25 & - \\
\hline & & Exhaustion (T4) & 2.31 & 1.01 & 24.83 & 4.75 & & Autonomy support (T4) & - & - & -.06 & - \\
\hline
\end{tabular}




\begin{tabular}{|c|c|c|c|c|c|c|c|c|c|}
\hline & & & & & & Autonomy (T4) & - & - & .01 \\
\hline & & & & & & Competence (T4) & - & - & .03 \\
\hline & & & & & & Relatedness (T4) & - & - & -.09 \\
\hline & & & & & & Subjective vitality (T4) & - & - & -.07 \\
\hline \multirow[t]{5}{*}{ Exhaustion (T5) } & 2.36 & 0.98 & 25.78 & 4.75 & & Autonomy support (T5) & - & - & -.22 \\
\hline & & & & & & Autonomy (T5) & - & - & -.07 \\
\hline & & & & & & Competence (T5) & - & - & -.14 \\
\hline & & & & & & Relatedness (T5) & - & - & -.39 \\
\hline & & & & & & Subjective vitality (T5) & - & - & -.18 \\
\hline \multirow[t]{5}{*}{ Exhaustion (T6) } & 2.24 & 0.89 & 19.77 & 2.39 & & Autonomy support (T6) & - & - & -.34 \\
\hline & & & & & & Autonomy (T6) & - & - & -.12 \\
\hline & & & & & & Competence (T6) & - & - & -.14 \\
\hline & & & & & & Relatedness (T6) & - & - & -.18 \\
\hline & & & & & & Subjective vitality (T6) & - & - & -.38 \\
\hline \multirow[t]{5}{*}{ Burnout (T1) } & 1.89 & 0.70 & 5.59 & 0.13 & $\begin{array}{c}\text { Spanish- } \\
\text { ABQ }\end{array}$ & Autonomy support (T1) & -.24 & - & - \\
\hline & & & & & & Controlling style (T1) & .38 & - & - \\
\hline & & & & & & Need satisfaction (T1) & -.34 & - & - \\
\hline & & & & & & Need thwarting (T1) & .53 & - & - \\
\hline & & & & & & Subjective vitality (T1) & -.16 & - & - \\
\hline \multirow[t]{2}{*}{ Burnout (T2) } & 1.98 & 0.75 & 8.69 & 0.36 & & Autonomy support (T2) &.- .33 & - & - \\
\hline & & & & & & Controlling style (T2) & .40 & - & - \\
\hline
\end{tabular}


Cheval, Chalabaev,

Quested, Courvoisier,

\& Sarrazin (2017)

110 male junior soccer

academy players $(M=16.54$

$S D=1.99$ )

Burnout (T1)

6.06

0.01

French-

ABQ

$2.16 \quad 0.46$

3.36

0.00

Burnout (T3)

Reduced

149 male junior soccer

academy players $(M=16.20$; $S D=2.00$ )

Uurran, Appleton,

Hill, \& Hall (2011)

Curran, Appleton,
Hill, \& Hall (2013)

González, GarcíaMerita, Castillo, \& Balaguer (2016)

Ex

\section{Exhaustion}

Devaluation

173 male junior soccer academy players $(M=15.46$ $S D=1.47$ )

Burnout

Reduced
Accomplishment
Exhaustion

Exhaustion

Devaluation

Burnout (T1)

360 male junior soccer

academy players $(M=12.60$; $S D=0.53$ )
ABQ

$1.63 \quad 0.73$

$2.00 \quad 0.55$

3.44

0.01

$\begin{array}{lll}2.10 & 0.62 & 7.35\end{array}$

$2.37 \quad 0.70$

18.41

0.11

0.99

$\begin{array}{ll}1.59 & 0.72\end{array}$

2.10

$1.88 \quad 0.70$

5.48

0.04

0.12
Need satisfaction (T2)

Need thwarting (T2)

Subjective vitality (T2)

No bivariate correlations

reported

Harmonious passion

\section{Obsessive passion}

Self-determination index

Burnout (T2)

Burnout (T3)

Burnout (T4)
$\mathrm{ABQ}$

\section{Harmonious passion}

Obsessive passion

Need satisfaction

SpanishABQ

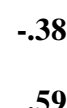

.59 
González, Tomás,

Castillo, Duda, \&

Balaguer (2017)

725 male junior soccer

academy players $(M=12.57$

Burnout (T2)

$S D=0.54) \dagger$
1.98

0.75

8.69

Spanis ABQ

Autonomy satisfaction (T2)
238 junior soccer academy players (30\% females; $M$ $17.0 ; S D=0.90)$

Podlog,

Wagnsson (2013) 171 male junior soccer
academy players $(M=16.17$;
$S D=1.57)$

Reduced

Accomplishment

$2.28 \quad 0.60$

11.5

Exhaustion

Devaluation

Reduced

Accomplishment

$\begin{array}{llllll}2.36 & 0.71 & 18.41 & 1.04 & \text { Swedish- } & \text { Hope }\end{array}$

$2.33 \quad 0.83$

20.90

2.22

$2.10 \quad 0.85$

14.46

$2.16 \quad 0.55$

6.30

0.04

Hill, Hall, Appleton, \& Kozub (2008)

$0.60-11.51$

$\begin{array}{lll}2.45 & 0.69 & 21.19\end{array}$

$1.74 \quad 0.70$

3.59

$2.35 \quad 0.69$ academy players $(M=14.40$;
1.25

0.21

\section{Perceived stress}

Positive affect

\section{Negative affect}

$\mathrm{ABQ}$

Personal standards perfectionism

Evaluative concerns

perfectionism

0.84

ABQ Self-oriented perfectionism
51 male junior soccer $S D=2.40$ )
Controlling style (T1) ${ }^{\mathrm{a}}$

Competence satisfaction (T2)

Relatedness satisfaction (T2)

Autonomy thwarting (T2)

Competence thwarting (T2)

Relatedness thwarting (T2)

Subjective vitality (T2)

$\mathrm{ABQ}$

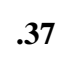

$-$.

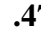

.52

$-.19$

$\begin{array}{lll}-.48 & -.27 & -.40\end{array}$

$\begin{array}{lll}.57 & .58 & .55\end{array}$

$\begin{array}{lll}-.45 & -.42 & -.47\end{array}$

$\begin{array}{llll}- & .33 & .36 & .31\end{array}$

$\begin{array}{llll}-.23 & -.33 & -.03 & -.22\end{array}$

$\begin{array}{lllll}.29 & .22 & .27 & .23\end{array}$ 


\begin{tabular}{|c|c|c|c|c|c|c|c|c|c|c|c|c|}
\hline & & Exhaustion & 2.28 & 0.81 & 18.67 & 1.70 & & Socially prescribed & - & .46 & .41 & .40 \\
\hline & & & & & & & & perfectionism & & & & \\
\hline & & Devaluation & 1.86 & 0.92 & 10.75 & 0.99 & & Unconditional self-acceptance & - & -.19 & -.31 & -.15 \\
\hline & & & & & & & & Satisfaction with goal progress & - & -.47 & -.29 & -.43 \\
\hline $\begin{array}{l}\text { Lai \& Wiggins (2003) } \\
\dagger \dagger\end{array}$ & $\begin{array}{l}73 \text { adult amateur soccer players } \\
\text { (53\% females; } M=19.38 ; S D \\
=1.45 \text { ) }\end{array}$ & Burnout (T1) & 2.09 & 0.52 & 4.09 & 0.01 & BIA & Age (T1) & .12 & - & - & - \\
\hline & & & & & & & & Years playing soccer (T1) & .22 & - & - & - \\
\hline & & & & & & & & Years of competitive soccer (T1) & .20 & - & - & - \\
\hline & & & & & & & & Years of club soccer (T1) & .20 & - & - & - \\
\hline & & Burnout (T2) & 2.05 & 0.47 & 2.12 & 0.00 & & Age (T2) & -.08 & - & - & - \\
\hline & & & & & & & & Years playing soccer (T2) & .20 & - & - & - \\
\hline & & & & & & & & Years of competitive soccer (T2) & .14 & - & - & - \\
\hline & & & & & & & & Years of club soccer (T2) & .08 & - & - & - \\
\hline & & Burnout (T3) & 2.15 & 0.58 & 7.08 & 0.07 & & Age (T3) & .12 & - & - & - \\
\hline & & & & & & & & Years playing soccer (T3) & .33 & - & - & - \\
\hline & & & & & & & & Years of competitive soccer (T3) & .08 & - & - & - \\
\hline & & & & & & & & Years of club soccer (T3) & .28 & - & - & - \\
\hline & & Burnout (T4) & 2.21 & 0.70 & 12.92 & 0.52 & & Age (T4) & .08 & - & - & - \\
\hline & & & & & & & & Years playing soccer (T4) & .22 & - & - & - \\
\hline & & & & & & & & Years of competitive soccer (T4) & .07 & - & - & - \\
\hline & & & & & & & & Years of club soccer (T4) & .17 & - & - & - \\
\hline & & Burnout (T5) & 2.31 & 0.76 & 18.41 & 1.36 & & Age (T5) & .09 & - & - & - \\
\hline
\end{tabular}


Li, Ivarsson, Stenling, \& Wu (2018)

10 male adult blind Paralympic soccer players $(M=24.80 ; S D$

$=2.53$ )

Lopes Verardi et al.

(2014; 2015)

71 male adult professional

soccer players $(M=22.77$; $S D$

$=3.98)$

Reduced

Accomplishment

\section{Exhaustion}

Devaluation

Reduced

63 male junior amateur soccer

players $(M=17.18 ; S D=0.84)$

Accomplishment

Exhaustion

Devaluation

Reduced

Accomplishment

Price \& Weiss (2000)
193 female junior amateur

$=1.10)$

Exhaustion

Devaluation
$1.51 \quad 0.46$

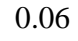

0.00

$\mathrm{ABQ}$

Years of club soccer (T5)

No bivariate correlations

reported

$\begin{array}{llllcl}2.08 & 0.50 & 3.29 & 0.01 & \begin{array}{c}\text { Portuguese- } \\ \text { ABQ }\end{array} & \text { No outcome variables reported } \\ 1.91 & 0.52 & 1.79 & 0.00 & & \\ 1.77 & 0.64 & 2.74 & 0.03 & & \\ 2.07 & 0.39 & 0.87 & 0.00 & & \\ 1.87 & 0.44 & 0.51 & 0.00 & & \\ 1.70 & 0.53 & 0.71 & 0.00 & & \\ 2.56 & 0.87 & 30.50 & 4.85 & \text { MBI } & \text { Perceived competence } \\ & & & & & \text { Anxiety } \\ 2.59 & 0.92 & 32.64 & 6.30 & & \text { Enjoyment } \\ 2.11 & 0.90 & 16.11 & 1.79 & & \end{array}$

Training and instruction

Democratic

Autocratic

Social support

Positive feedback

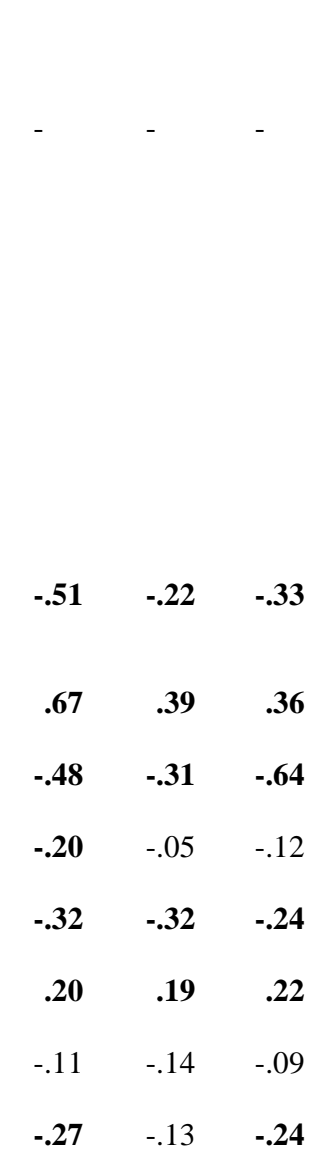




\begin{tabular}{|c|c|c|c|c|c|c|c|c|c|c|c|c|}
\hline \multirow[t]{8}{*}{$\begin{array}{l}\text { Smith, Hill, \& Hall (in } \\
\text { press) }\end{array}$} & \multirow[t]{8}{*}{$\begin{array}{l}162 \text { male junior soccer } \\
\text { academy players }(M=16.15 \\
S D=1.84)\end{array}$} & $\begin{array}{l}\text { Reduced } \\
\text { Accomplishment (T1) }\end{array}$ & 2.16 & 0.64 & 9.51 & 0.20 & \multirow[t]{8}{*}{$\mathrm{ABQ}$} & Self-oriented perfectionism (T1) & - & -.25 & -.32 & -.40 \\
\hline & & Exhaustion (T1) & 2.05 & 0.70 & 8.69 & 0.26 & & Socially prescribed & - & .27 & .24 & .16 \\
\hline & & & & & & & & perfectionism (T1) & & & & \\
\hline & & Devaluation (T1) & 1.55 & 0.51 & 0.23 & 0.00 & & Depressive symptoms (T1) & - & .51 & .44 & .44 \\
\hline & & $\begin{array}{l}\text { Reduced } \\
\text { Accomplishment (T2) }\end{array}$ & 2.18 & 0.64 & 10.03 & 0.23 & & Self-oriented perfectionism (T2) & - & -.17 & -.16 & -.19 \\
\hline & & Exhaustion (T2) & 2.02 & 0.75 & 9.51 & 0.41 & & Socially prescribed & - & .09 & .26 & .27 \\
\hline & & & & & & & & perfectionism (T2) & & & & \\
\hline & & Devaluation (T2) & 1.52 & 0.61 & 0.75 & 0.00 & & Depressive symptoms (T2) & - & .65 & .40 & .53 \\
\hline \multirow[t]{3}{*}{$\begin{array}{l}\text { Tabei, Fletcher, \& } \\
\text { Goodger (2012) }\end{array}$} & $\begin{array}{l}98 \text { male adult semi-professional } \\
\text { soccer players }(50=\text { English; } \\
48=\text { Japanese; } M=20.25 ; S D \\
=1.20)\end{array}$ & $\begin{array}{l}\text { Reduced } \\
\text { Accomplishment }^{\mathrm{Av}}\end{array}$ & 2.92 & 0.52 & 44.04 & 1.88 & \multirow[t]{3}{*}{$\begin{array}{l}\text { ABQ and } \\
\text { Japanese- } \\
\text { ABQ }\end{array}$} & No outcome variables reported & - & - & - & - \\
\hline & & Exhaustion $^{\mathrm{Av}}$ & 2.84 & 0.56 & 38.59 & 1.92 & & & & & & \\
\hline & & Devaluation $^{\mathrm{Av}}$ & 2.73 & 0.60 & 32.64 & 1.70 & & & & & & \\
\hline \multirow[t]{5}{*}{ Yildiz (2011) } & $\begin{array}{l}107 \text { male adult professional } \\
\text { soccer players }(M=25.70 ; \text { no } \\
S D \text { reported })\end{array}$ & Burnout & 2.47 & 0.57 & 17.62 & 0.36 & \multirow[t]{5}{*}{$\begin{array}{l}\text { Abbreviated } \\
\text { BM }\end{array}$} & Marital status & -.12 & - & - & - \\
\hline & & & & & & & & Age & .55 & - & - & - \\
\hline & & & & & & & & Educational status & .03 & - & - & - \\
\hline & & & & & & & & Professional playing experience & .53 & - & - & - \\
\hline & & & & & & & & Leader-member exchange & -.44 & - & - & - \\
\hline
\end{tabular}

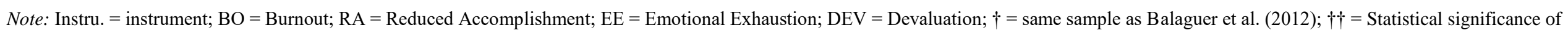
correlations not provided in the original study. In the table they are calculated based on sample size; ${ }^{\mathrm{Av}}=$ Average burnout score across time points or across samples; $\mathrm{ABQ}=\mathrm{Athlete} \mathrm{Burnout}$

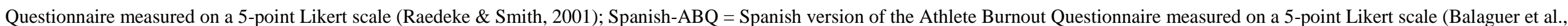

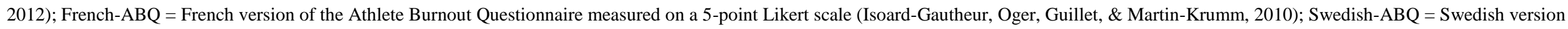


of the Athlete Burnout Questionnaire measured on a 5-point Likert scale (Smith, Gustafsson, \& Hassmen, 2010); BIA = The Burnout Inventory for Athletes measured on a 5-point Likert scale (Van Yperen, 1997); Portuguese-ABQ = Portuguese version of the Athlete Burnout Questionnaire measured on a 5-point Likert scale (Pires, Brandão, \& Silva, 2006); MBI = Maslach Burnout Inventory measured on a 5-point Likert scale (Maslach \& Jackson, 1981a, b); Japanese-ABQ = Japanese version of the Athlete Burnout Questionnaire measured on a 5-point Likert scale (Tabei, Fletcher, \&

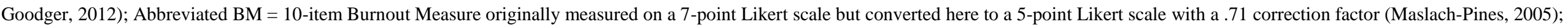
all correlations with burnout for longitudinal studies are within timepoints unless otherwise indicated; ${ }^{\mathrm{a}}=$ correlations between burnout at time two and outcome variables measured at time one. 